\title{
Baseline Neutron Logging Measurements in the Drift Scale Test
}

\author{
W. Lin \\ R. Carlson \\ D. Neubaurer
}

January 1998

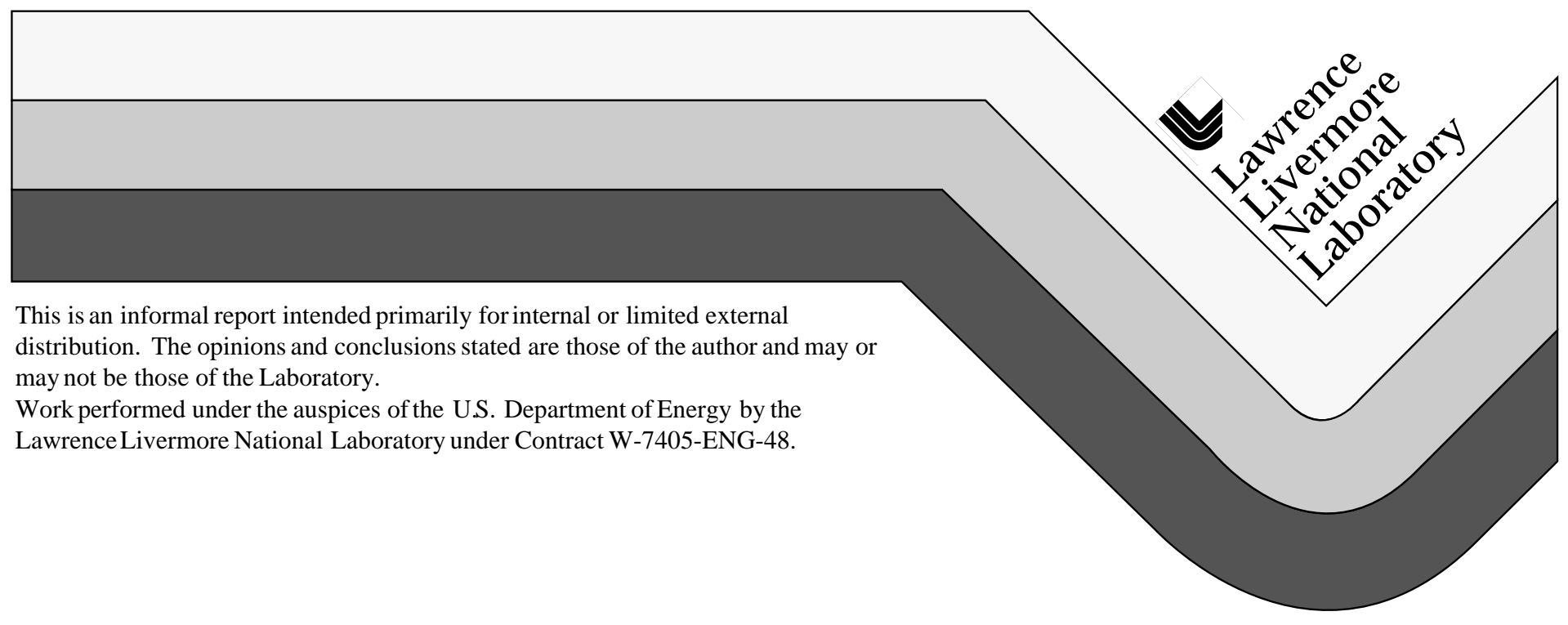




\section{DISCLAIMER}

This document was prepared as an account of work sponsored by an agency of the United States Government. Neither the United States Government nor the University of California nor any of their employees, makes any warranty, express or implied, or assumes any legal liability or responsibility for the accuracy, completeness, or usefulness of any information, apparatus, product, or process disclosed, or represents that its use would not infringe privately owned rights. Reference herein to any specific commercial product, process, or service by trade name, trademark, manufacturer, or otherwise, does not necessarily constitute or imply its endorsement, recommendation, or favoring by the United States Government or the University of California. The views and opinions of authors expressed herein do not necessarily state or reflect those of the United States Government or the University of California, and shall not be used for advertising or product endorsement purposes.

This report has been reproduced directly from the best available copy.

Available to DOE and DOE contractors from the Office of Scientific and Technical Information P.O. Box 62, Oak Ridge, TN 37831

Prices available from (423) 576-8401

Available to the public from the National Technical Information Service

U.S. Department of Commerce 5285 Port Royal Rd. Springfield, VA 22161 


\title{
Baseline Neutron Logging Measurements in the Drift Scale Test
}

\section{Milestone SPY195M4}

\author{
Wunan Lin, Richard Carlson, and Dan Neubaurer
}

\section{Introduction}

The Drift Scale Test (DST) is one of the thermal tests being conducted in the Exploratory Studies Facility (ESF). One of the objectives of the DST is to study the coupled thermal-mechanicalhydrological-chemical (TMHC) processes in the ESF at the repository horizon of the potential high-level nuclear waste repository in Yucca Mountain, Nevada. The objectives, the test design, and the test layouts of the DST are included in the test design report by CRWMS $M \& O$ Contractor ${ }^{[1]}$. The configuration of the DST includes a declining Observation Drift driven mostly east and downward from main tunnel in the ESF, at about $2.827 \mathrm{~km}$ from the North portal. The downward slope of the Observation Drift (11.5 to 14.0 percent) ensures a minimum $10 \mathrm{~m}$ of middle nonlithophysal Topopah Spring Tuff as the overburden for the DST. The length of the Observation Drift is about $136 \mathrm{~m}$. At the elevation of the DST crown (nominally $10 \mathrm{~m}$ below the upper extent of the middle nonlithophysal Topopah Spring Tuff) the Connecting Drift breaks out to the north from the Observation Drift, $136 \mathrm{~m}$ from the main tunnel of the ESF. The Connecting Drift extends approximately $40 \mathrm{~m}$ to the north from the Observation Drift. A Heater Drift breaks out westward from the Connecting Drift at about $30 \mathrm{~m}$ from the Observation Drift. The Heater Drift consists of an $11 \mathrm{~m}$ long entry, which includes a plateloading niche, and a $47 \mathrm{~m}$ long heated drift. The nominal diameter of the drifts is $5 \mathrm{~m}$. The detail configuration of the DST, including diagrams showing the drift and borehole layout, is included in the test design report by CRWMS M\&O Contractor [1]

Thermal neutron logging is a method used to determine moisture content in rocks and soils and will be used to monitor moisture content in boreholes ESF-HD-NEU-1 to ESF-HD-NEU-10 (Boreholes \#47 to 51 and 64 to 68), ESF-HD-TEMP-1 (Borehole \#79), and ESF-HD-TEMP-2 (Borehole \#80) in the DST. The neutron probe contains a source of high energy neutrons and a detector for slow (thermal) neutrons. Water present in rocks slows down the neutrons making them detectable (because of the presence of hydrogen). Thus, higher counts (or a positive difference in counts relative to background or pre-heat levels) indicate higher water content (or 
increased water content over background). The probe used in these baseline measurements is a Campbell Pacific Nuclear (CPN) model 503DR. The $3.81-\mathrm{cm}$ (1.5 inch) diameter probe was also utilized for the Single Heater Test (Serial Number: H37067677). Under ambient conditions the sampling volume has a diameter approximately $15 \mathrm{~cm}$ surrounding the probe, increasing as moisture content decreases. Measurements are sensitive to the presence of elements that have large neutron capture cross-sections, such as chlorine and boron. The uncertainty of the neutron logging is about 3 to $5 \%$ in water content, by considering the counting statistics and other uncertainties, such as location of the tool. A new neutron tool made by LND, Inc. (Model LND 25147) has been purchased for measuring the neutron counts of the rock mass during the heating and cooling phases of the DST. The LND tool is designed for operating at temperatures to $200^{\circ} \mathrm{C}$.

For boreholes ESF-HD-NEU-1 to ESF-HD-NEU-10 of the DST a Teflon tube was inserted into the boreholes and grouted into place. The Teflon tube permits easy insertion, placement, and removal of the tool. Calibration of both the CPN tool and the LND tool in the Teflon-grout assembly identical to that used in the holes will be conducted. For boreholes ESF-HD-TEMP-1 (Hole \#79) and ESF-HDTEMP-2 (Hole \#80) one RTD bundle was attached to the outside of the Teflon liner, and the assembly was grouted in place in the holes. Calibrations of the neutron tools in the Teflon liner-RTD-grout assembly identical to that used in the holes 79 and 80 will also be conducted. The calibration information will be used to convert the neutron counts reported in this document into fraction volume water content.

\section{Measurement Procedures}

The following procedure describes the method of collecting the baseline neutron data of the DST. We used the $3.81-\mathrm{cm}$ diameter probe (the CPN probe) and a counting time of 16 seconds. Standard counts, which are the neutron counts when the tool is in the tool holder away from any influence of the rock mass to be measured, were measured and recorded immediately prior to, and subsequent to performing measurements. The neutron probe was placed in a borehole at a specific location (depth) and the neutron count recorded in a scientific notebook as well as electronically in the device memory. Upon completion of the test, data was downloaded to a computer and the data values checked against the hand recorded 
values. Data were recorded at depth intervals of $10 \mathrm{~cm}$ in each

borehole. The procedures are described in TIP-NF- $31^{[2]}$.

Two baseline measurements were conducted in each one of the 12 holes after the holes were grouted. In Hole ESF-HD-TEMP-2 one additional measurement was conducted before the hole was grouted.

\section{The Baseline Data and Discussion}

The baseline neutron counts in the 12 boreholes in the DST are shown in Figures 1 to 12, for boreholes ESF-HD-NEU-1 to ESF-HDNEU-10 and ESF-HD-TEMP-1 to ESF-HD-TEMP-2 respectively. Each one of these figures presents the two baseline neutron counts in the hole. In addition to the baseline neutron counts in Hole ESF-HDTEMP-2, Figure 12 also shows the neutron counts in this hole before it was grouted. The neutron counts of the two baseline measurements in each hole agree well to each other. The low neutron counts at the collar of some of the holes (Figures 3, 4, and 11) may be influenced by the environment outside of the hole. They will be closely watched during the logging in the heating phase of the DST. Figure 12 shows that the deeper part of Hole ESF-HDTEMP-2 (deeper than about $52 \mathrm{~m}$ from collar) was not grouted.

\section{Summary}

Successful baseline neutron measurements have been conducted in all of the neutron holes in the DST. All of the baseline data have been presented in this report. These neutron count data will be converted into the baseline water content of the rock mass when the neutron tools are calibrated in the exact borehole configuration of the DST.

\section{Future Plans}

The DST progresses into the heating phase. The neutron logging will be continued using the LND tool. During the first measurement using the LND tool, the CPN tool will also be used again to provide a comparison of the neutron counts from the two tools. Calibrations of both the LND tool and the CPN tool in the exact Teflon-grout and Teflon-grout-RTD assemblies, as used in the DST, will be conducted. Then the baseline neutron counts and the future neutron counts during the heating phase will be converted into fraction volume water contents. 


\section{References}

[1]. Civilian Radioactive Waste Management System Management and Operation Contractor (OCRWM M\&O), 1996a, Test Design, Plans, and Layout for the First ESF Thermal Test, Rev. 1, BAB00000001717-4600-00025, TRW Environmental Safety System, Inc., Las Vegas, NV 89109.

[2]. Lawrence Livermore National Laboratory Yucca Mountain Project Technical Implementation Plan, 1994, Neutron and Gamma (Density) Logging in Welded Tuff, TIP-NF-31, Riv. 1, Lawrence Livermore National Laboratory, University of California, Livermore, CA 94550. 


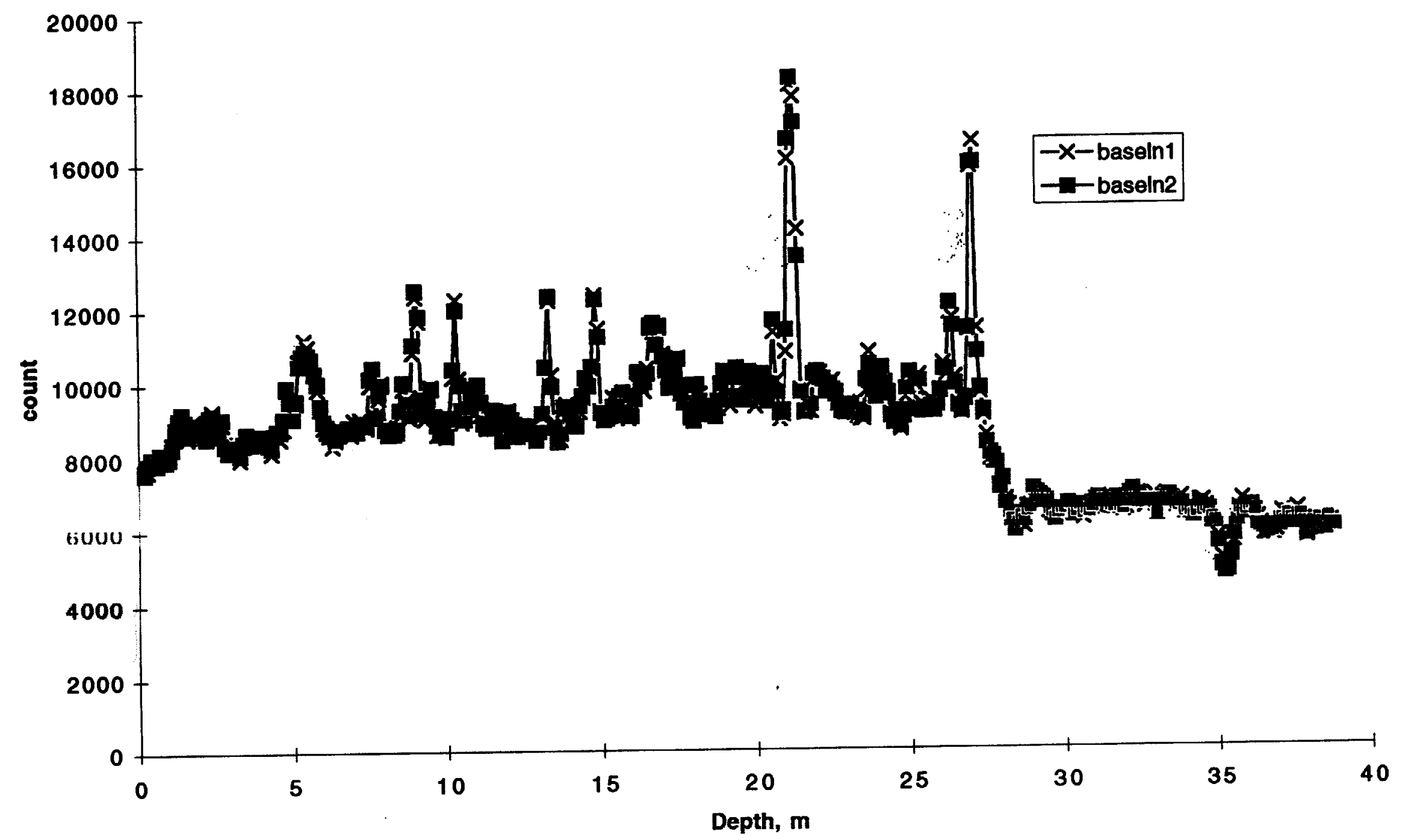

Figure 1. The baseline neutron counts as a function of depth from collar of ESF-HD-NEU-1 of the DST, measured on 10/9/97 (baseln1) and 10/27/97 (baseln2). 


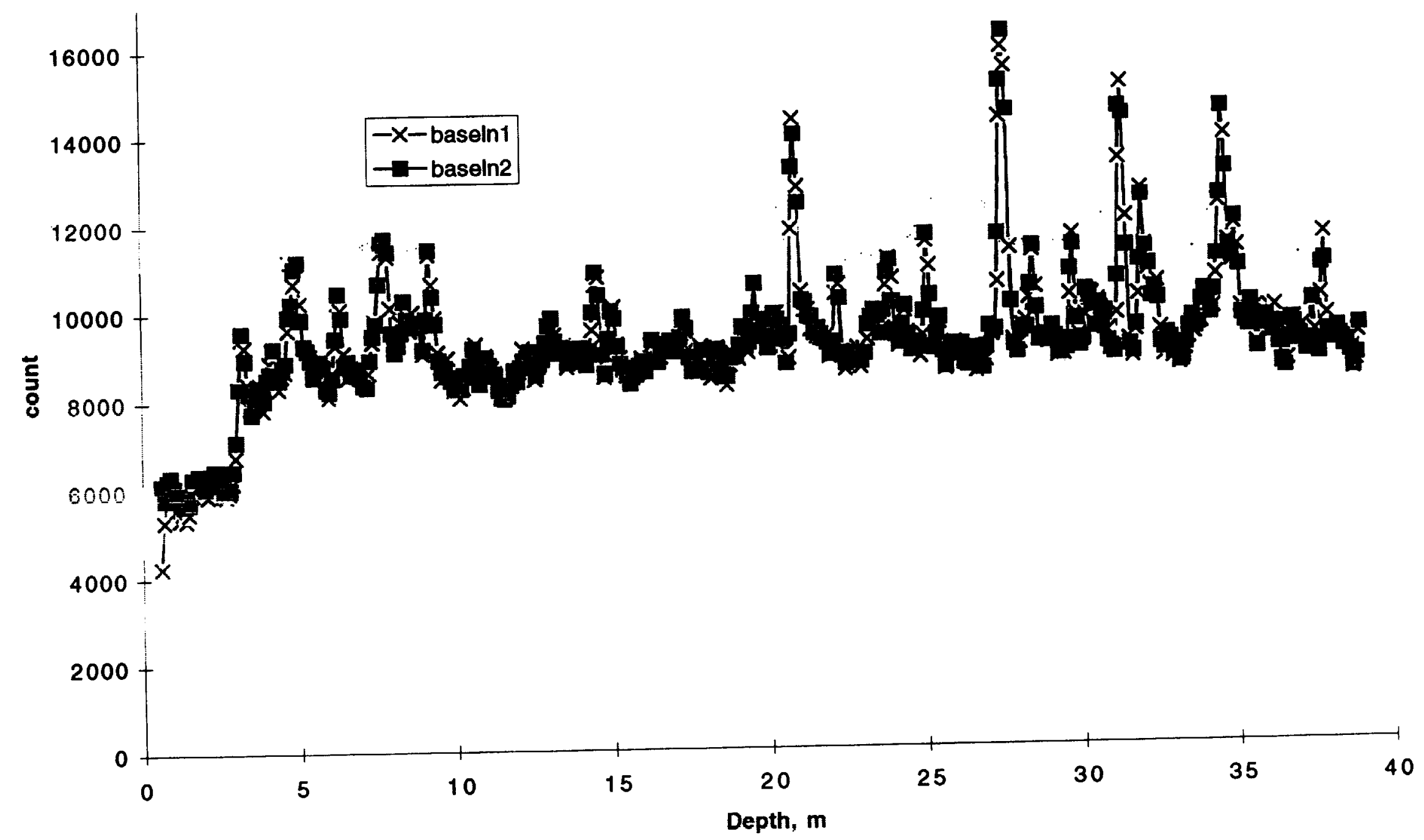

Figure 2. The baseline neutron counts of ESF-HD-NEU-2 of the DST as a function of depth from collar, measured on 10/21/97 (baseln1) and 10/28/97 (baseln2). 


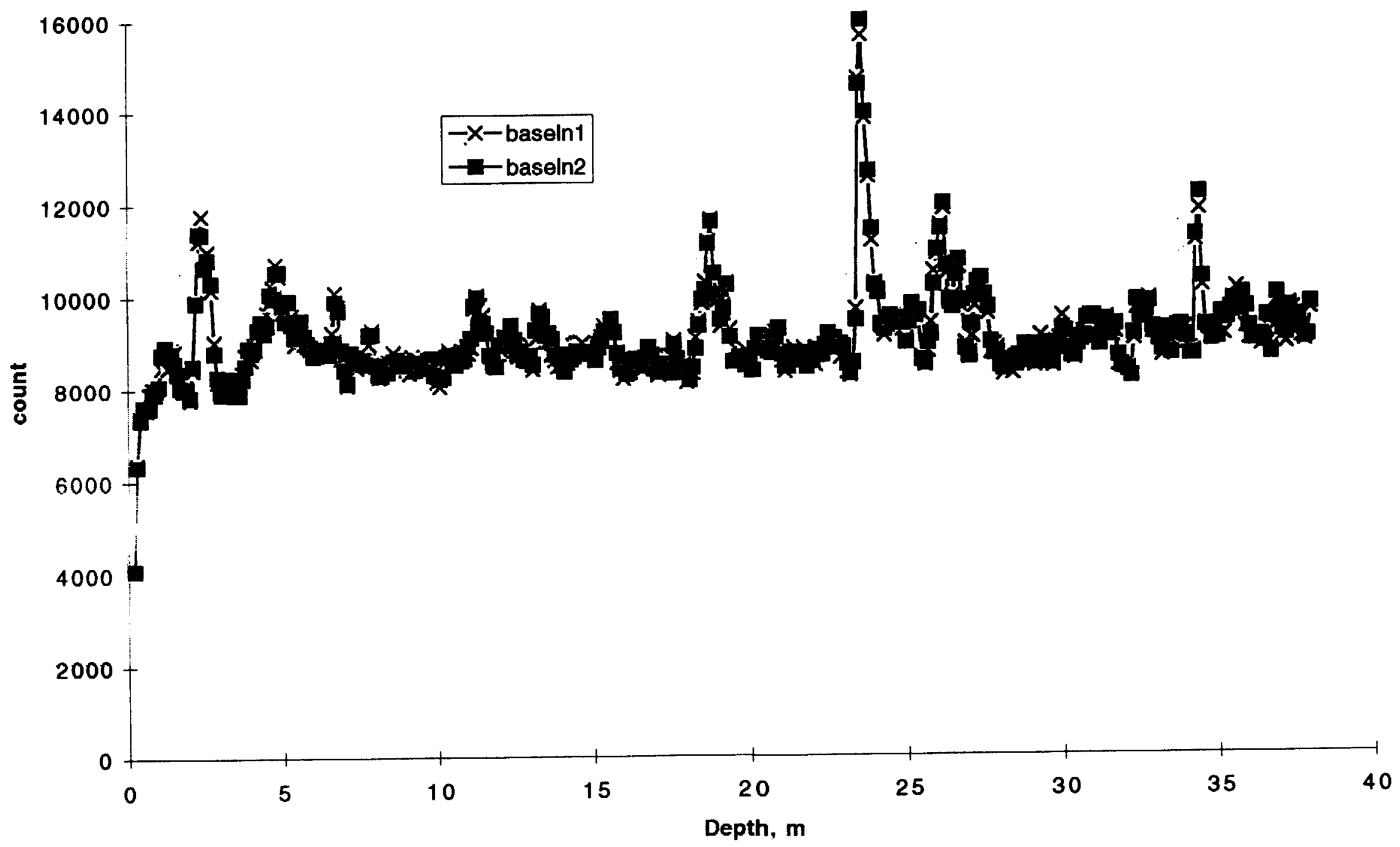

Figure 3. The baseline neutron counts of ESF-HD-NEU-3 of the DST as a function of depth from collar, measured on 10/13/97 (baseln1) and 10/27/97 (baseln2). 


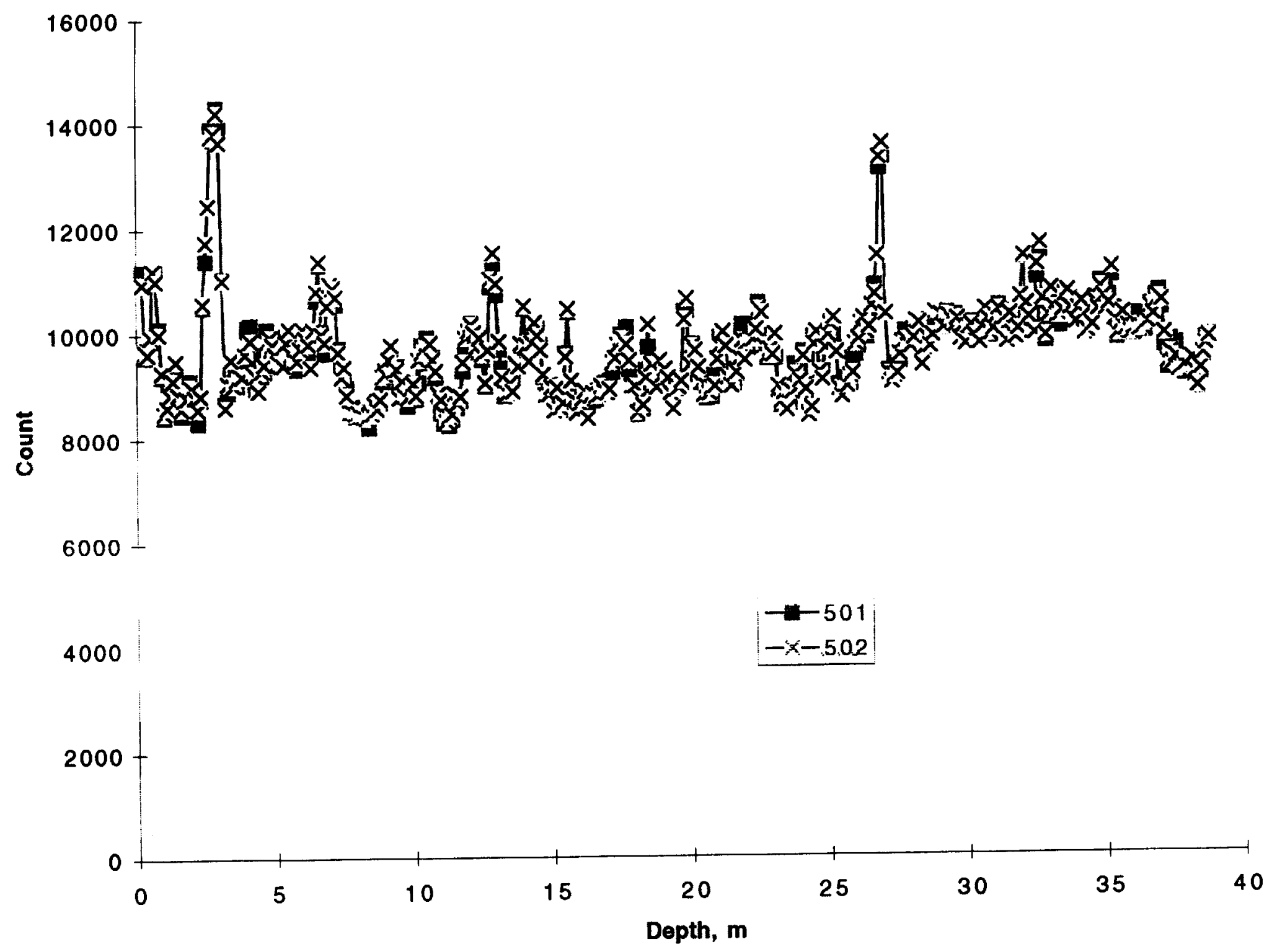

Figure 5. The baseline neutron counts in ESF-HD-NEU-5 of the DST as a function of depth from collar, measured on 10/14/97 (501) and $10 / 23 / 97$ (502). 


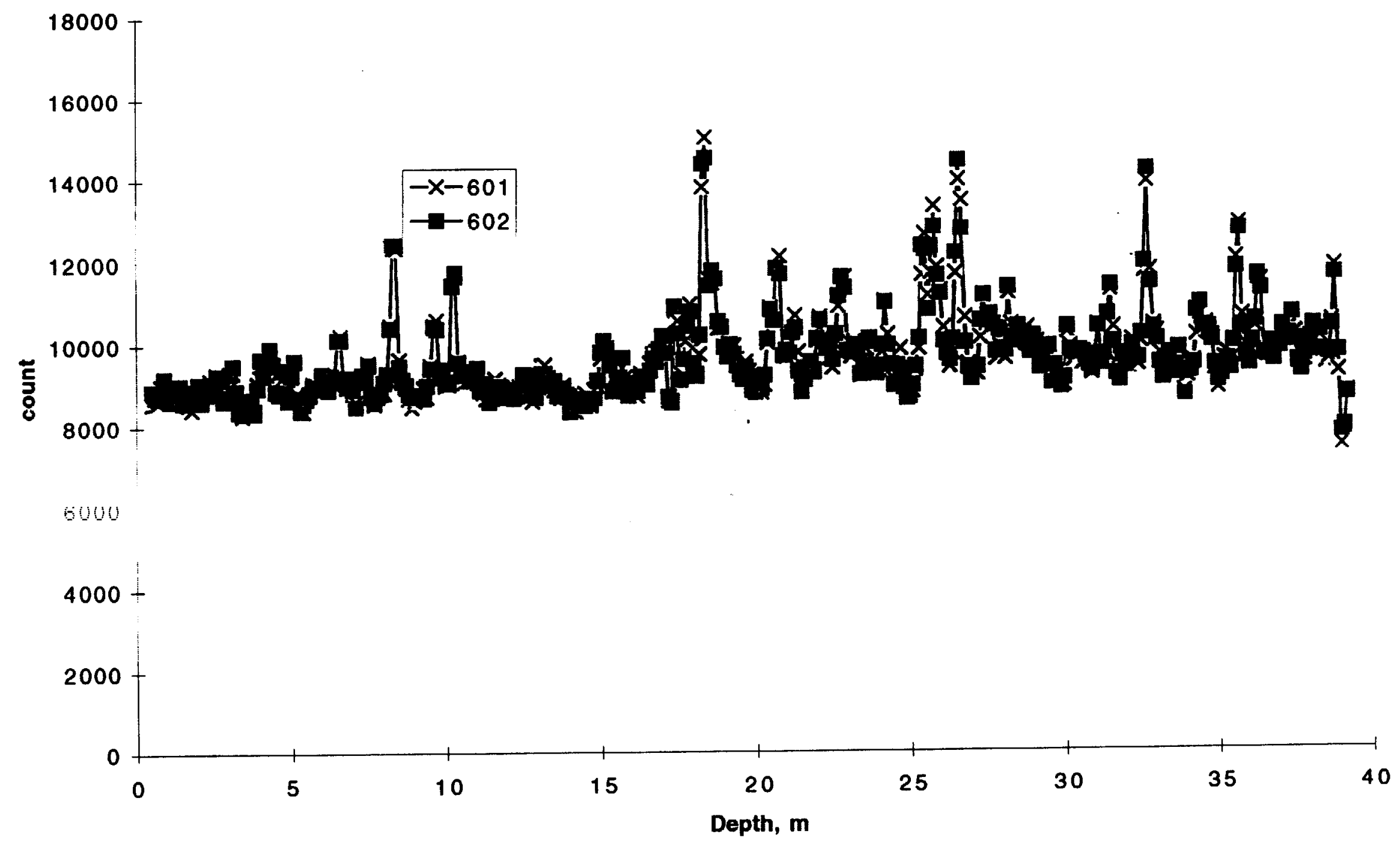

Figure 6. The baseline neutron counts in ESF-HD-NEU-6 of the DST as a function of depth from collar, measured On $9 / 30 / 97$ (601) and 10/15/97 (602). 


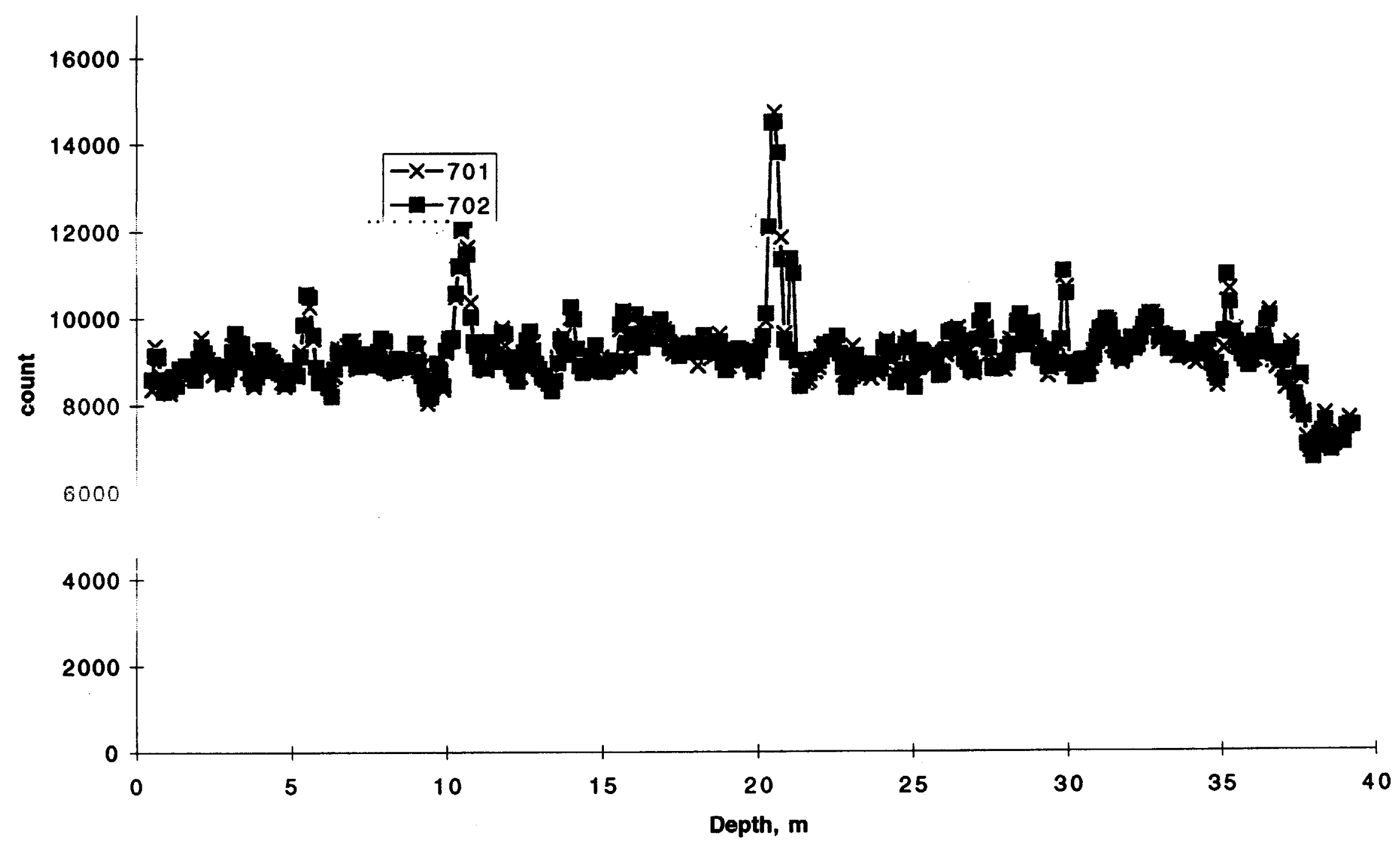

Figure 7. The baseline neutron counts in ESF-HD-NEU-7 of the DST as a function of depth from collar, measured on 9/30/97 (701) and 10/15/97 (702). 


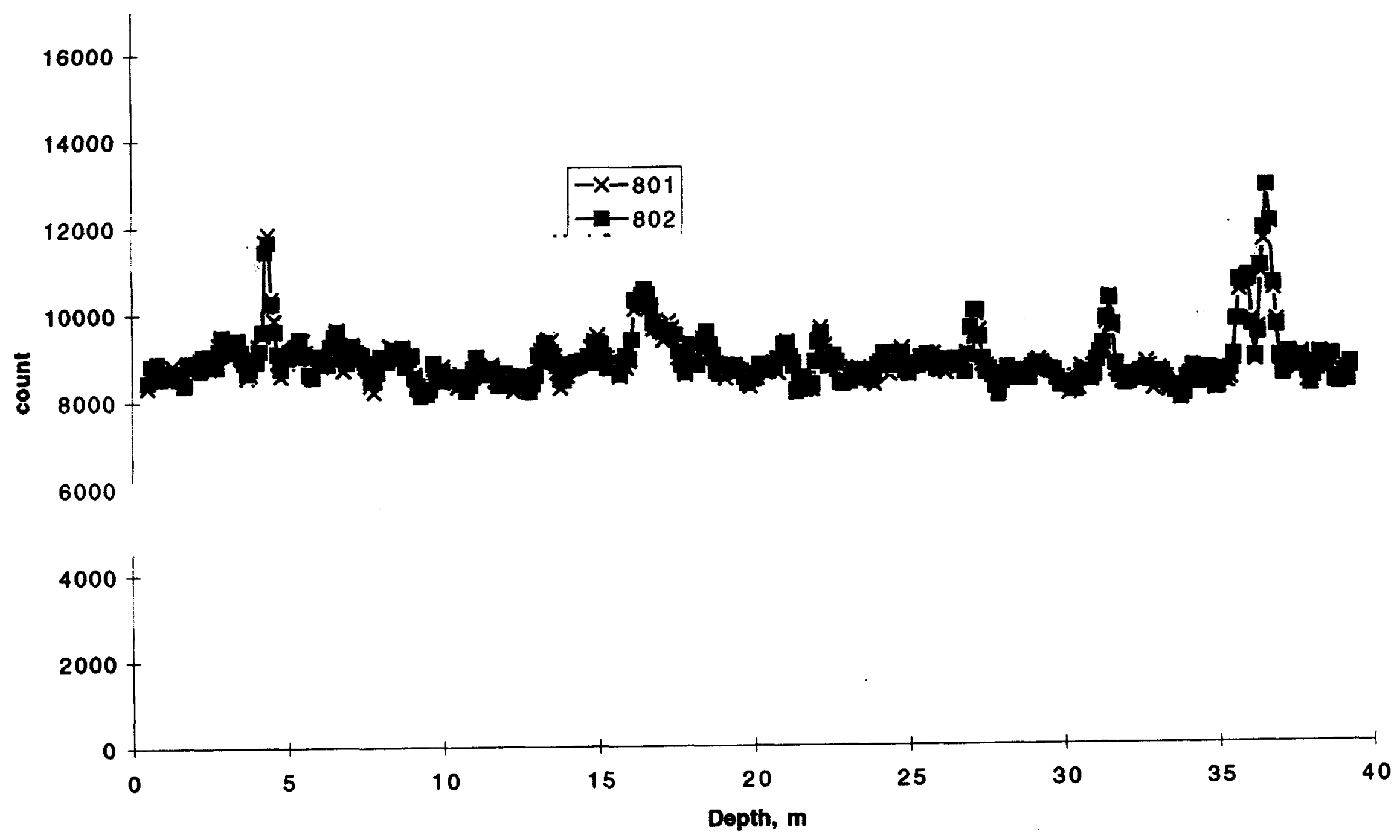

Figure 8. The baselind neutron counts in ESF-HD-NEU-8 of the DST as a function of depth from collar, measured on 10/2/97 (801) and 10/16/97 (802). 


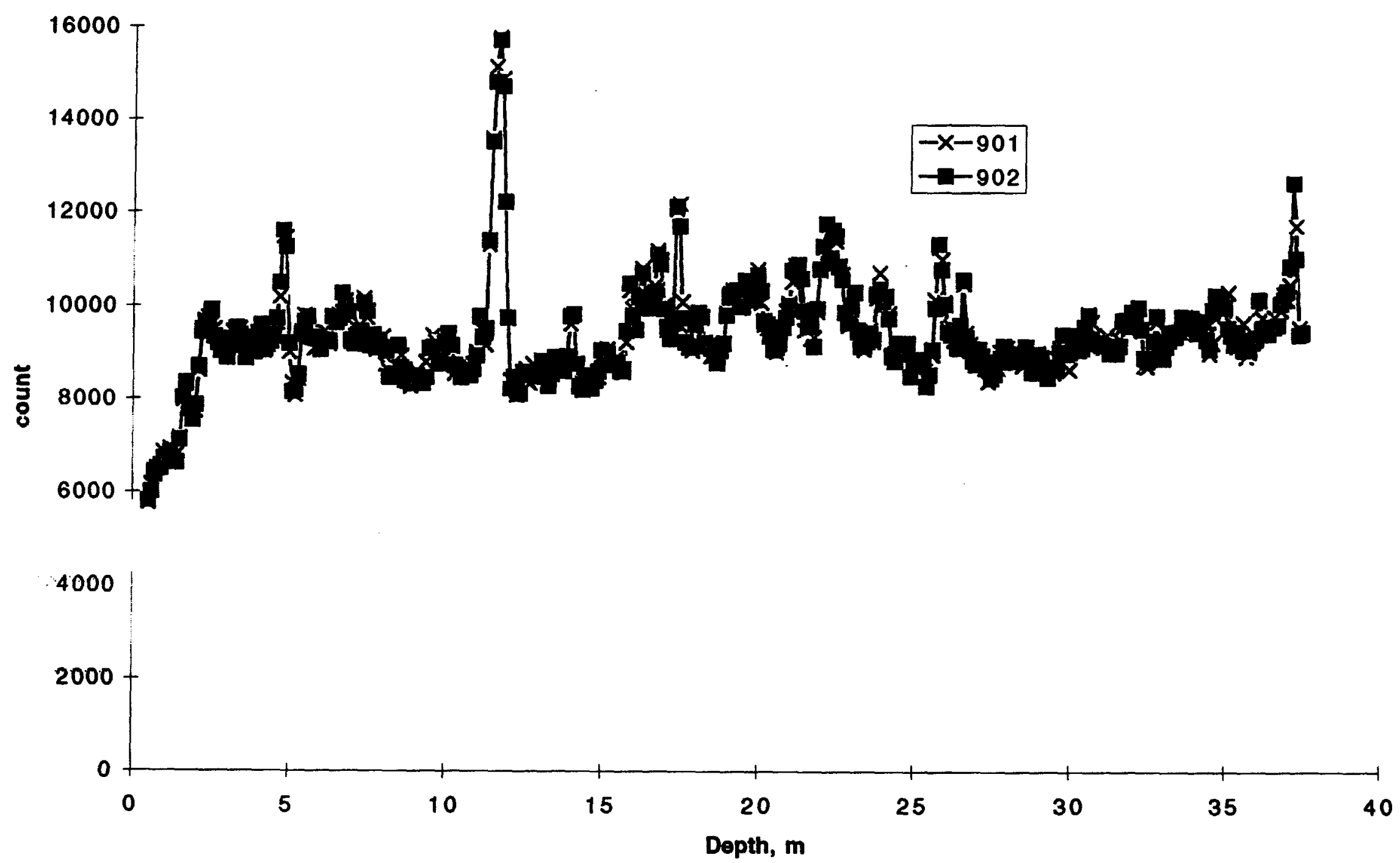

Figure 9. The baseline neutron counts in ESF-HD-NEU-9 of the DST as a functin of depth from collar, measured on 10/2/97 (901) and 10/6/97 (902). 


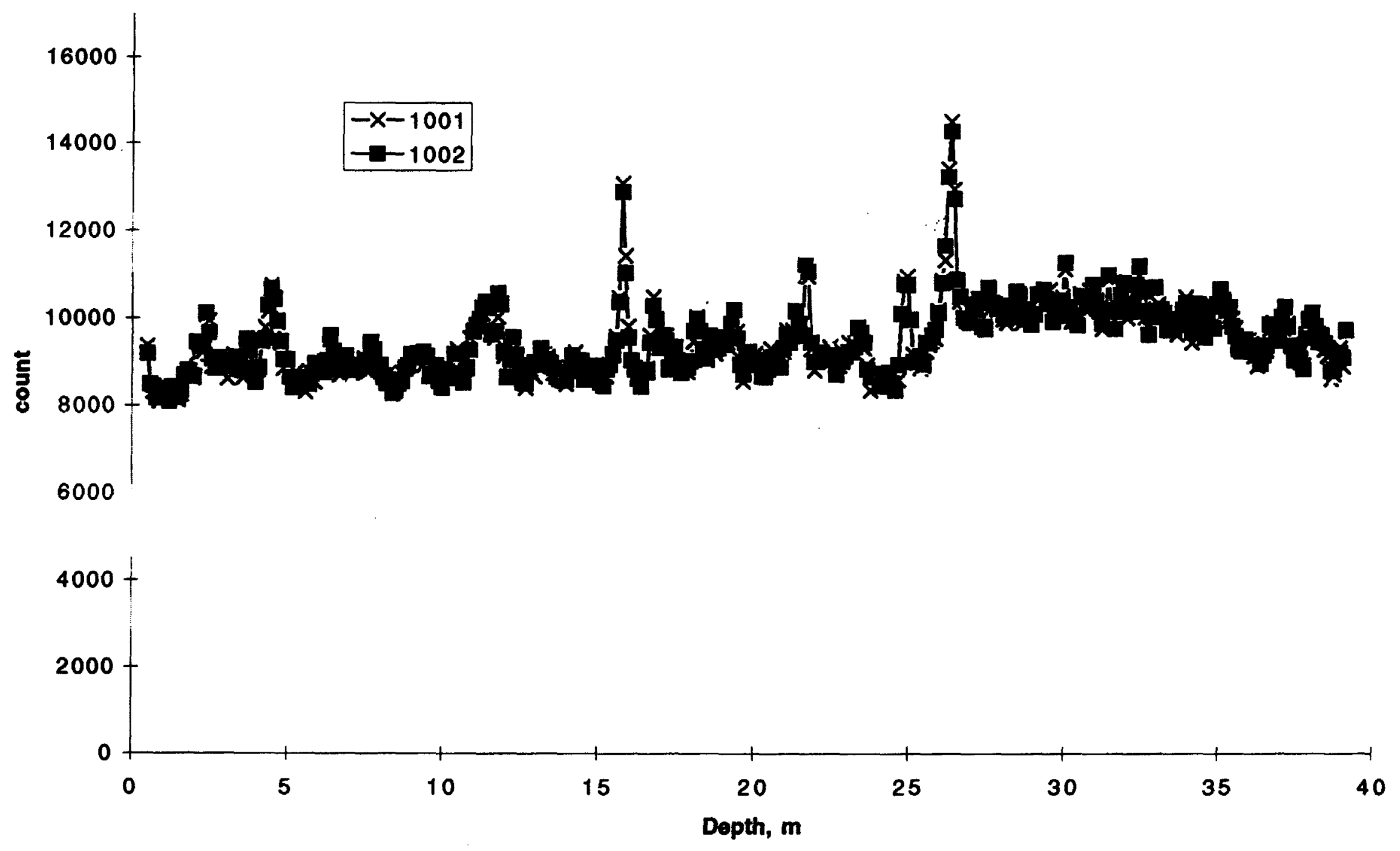

Figure 10. The baseline neutron counts in ESF-HD-NEU-10 of the DST as a function of depth from collar, measured on 10/2/97 (1001) and 10/21/97 (1002). 


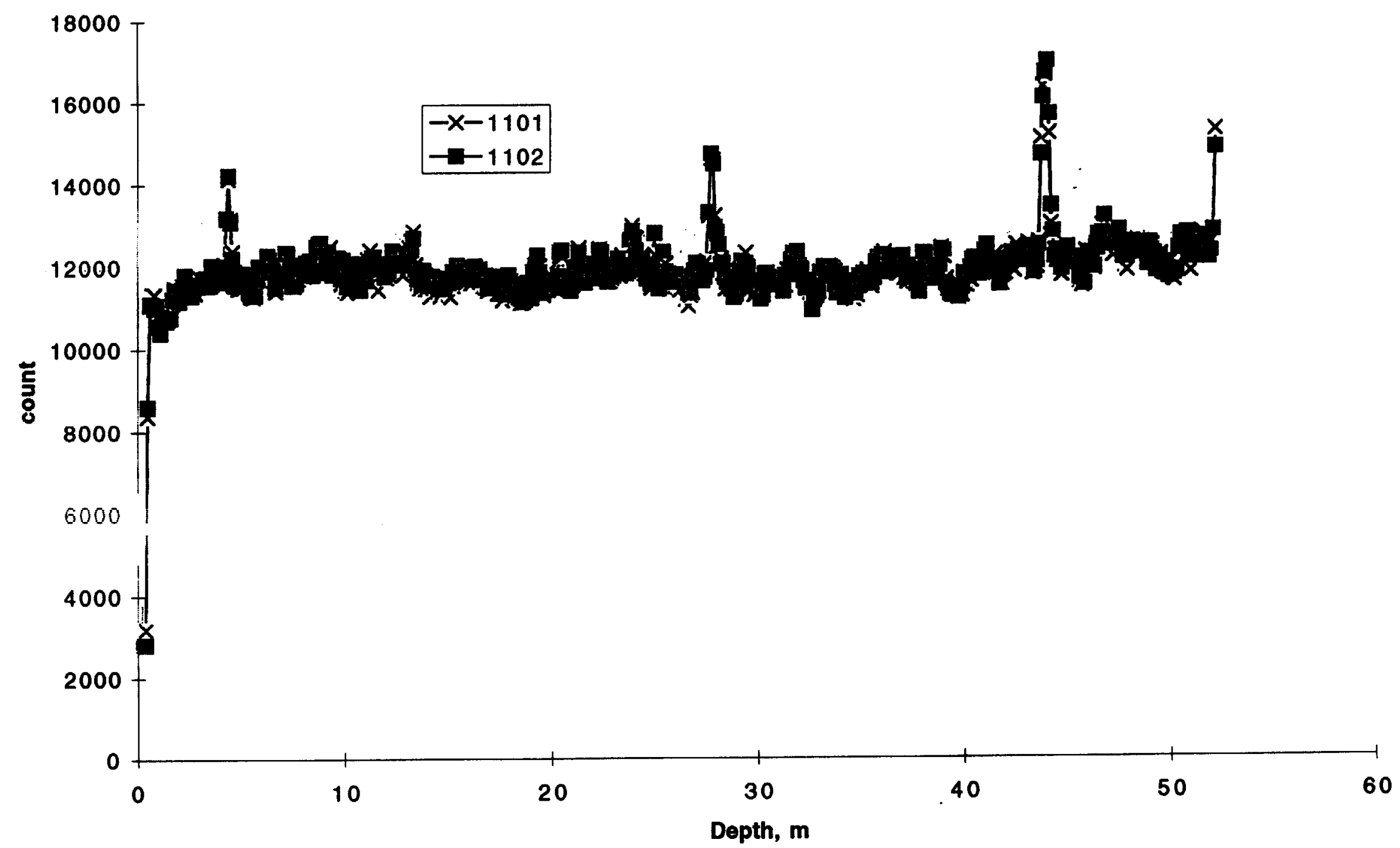

Figure 11. The baseline neutron counts in ESF-HD-TEMP-1 (Borehole \#79) of the DST as a function of depth from collar, measured on $10 / 8 / 97$ (1101) and 11/4/97 (1102). 


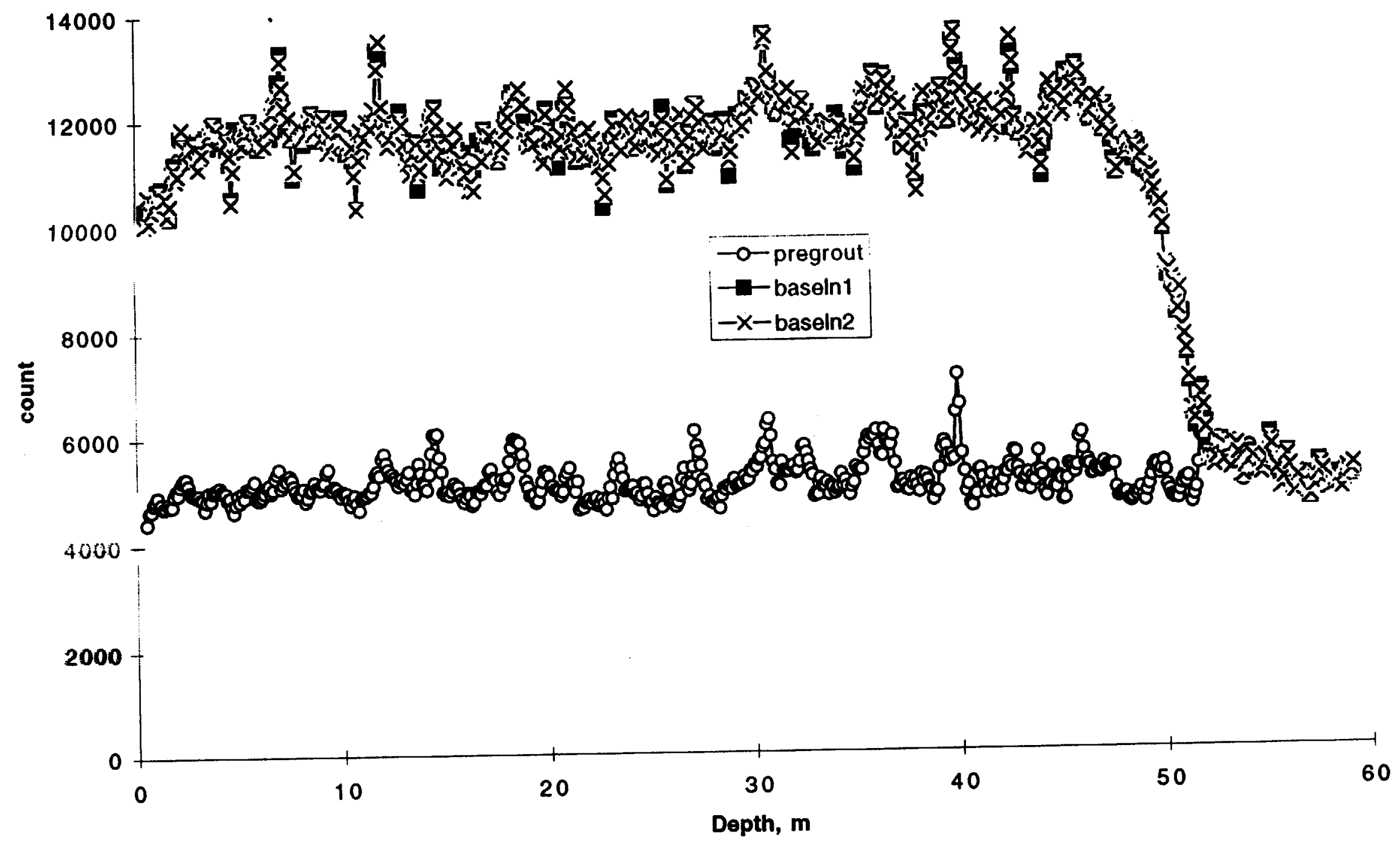

Figure 12. The baseline neutron counts in ESF-HD-TEMP-2 (Borehole \#80) of the DST as a function of depth from collar measured on $8 / 25 / 97$ (pregrout), 10/8/97 (baseln1), and 11/4/97 (baseln2). 


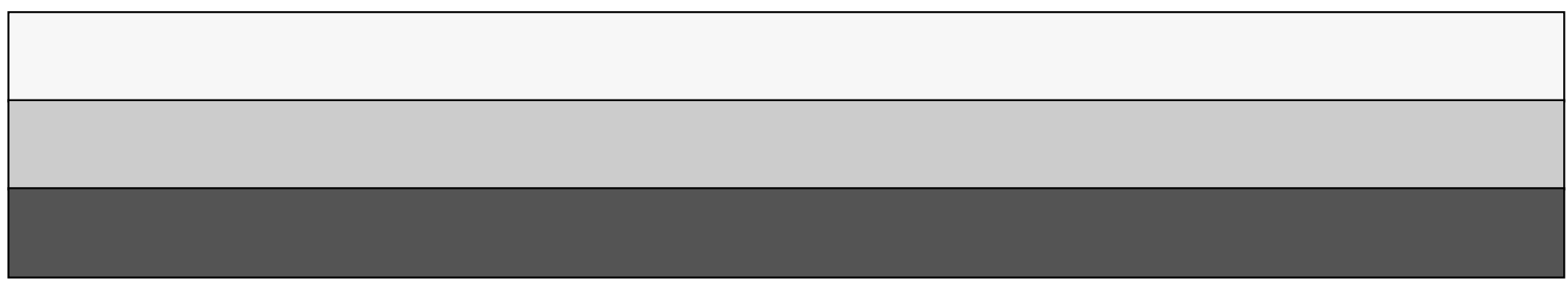

